\title{
RESEARCH-BASED DEVELOPMENT OF CONSUMER DRUG INFORMATION PAMPHLET AT TRIBHUVAN UNIVERSITY TEACHING HOSPITAL IN NEPAL
}

\author{
Joshi M $\mathbf{P}^{1}$, Johnson $\mathrm{K} \mathrm{W}^{2}$, Blum $\mathrm{N} \mathrm{L}^{3}$ \\ Regmi $B^{1}$, Khakurel $B^{4}$
}

\section{ABSTRACT}

Considering the generally low priority given to educating consumers in Nepal and also as a part of its commitment towards consumer awareness, the Drug Information Unit of Tribhuvan University Teaching Hospital (TUTH) developed and distributed a consumer education pamphlet on basic do's and don'ts about medicines. The methodology of the development of this pamphlet included: (1) a questionnaire interview of visitors (n=604) of patients admitted to TUTH to find out the existing level of knowledge on basic facts about medicines, (2) development of a draft pamphlet, mainly based on the findings of this baseline survey, (3) pretesting of the draft pamphlet on patients' visitors $(n=614)$ at TUTH and subject experts $(n=13)$ to get their comments and suggestions on the text, language, drawings and presentation, and (4) revision of the pamphlet based on the pretest and its final printing. The present work thus represents a research-based approach to the development of public education material.

Key Words: Rational drug use; public education; consumer awareness; drug information pamphlet; Nepal.

1. T. U. Teaching Hospital, Institute of Medicine, Tribhuvan University, Kathmandu, Nepal.

2. Management Sciences for Health, Arlington, VA, USA.

3. United States Pharmacopeia, Rockville, MD, USA.

4. HMG/WHO Collaborative Essential Drugs Program, WHO, UN Building, Lalitpur, Nepal.

Address for correspondence : Professor Mohan P. Joshi

Head of the Dept. of Clinical Pharmacology \&

Director, Drug Information Center (DIASP Center)

Tribhuvan University Teaching Hospital, Institute of Medicine

P. O. Box: 3578, Maharajgunj, Kathmandu, Nepal

Tel: 977-1-416959, Fax: 977-1-418186

Emails: mohan_p_joshi@hotmail.com, mpjoshi@healthnet.org.np 


\section{INTRODUCTION}

Tribhuvan University Teaching Hospital (TUTH), which is a part of the Institute of Medicine, ${ }^{1}$ is a major tertiary care hospital in Nepal providing health care to more than 250,000 people annually. A Drug Information Unit (DIU) was established in this Hospital in 1994 with a view to providing independent drug and therapeutic information. ${ }^{2,3}$ Besides doing the Unit's regular work of providing question-answer service and producing drug bulletin, the DIU staff have contributed to various other drug-related activities inside and outside the Hospital. $^{4-8}$ In 1996, the DIU contributed to the establishment of Drug Information Network of Nepal (DINoN) as a founder member. ${ }^{9,10}$ The Unit has now merged into the Drug Information, Antimicrobial Surveillance and Pharmacovigilance Center (DIASP Center), which is an independent center established recently within TUTH.

The drug information service at TUTH, which was initially focused on providing information to health care providers, is now expanding towards raising the level of public awareness regarding drug use. Public education is an important prerequisite for improvement in drug use. ${ }^{11}$ No national drug policy can achieve full success without adequate consumer education. ${ }^{12}$

Different methods have been used to carry out public education on drug use. These include: workshops/training; printed materials such as booklets, leaflets, posters, pamphlets and flipcharts; mass media such as newspaper, radio, and television; puppet shows and street theaters; telephone question-answer services; community meetings; health center talks; and educational programs at schools. ${ }^{13}$ The present work done at TUTH represents an effort at developing researchbased print material for the general public. The methodology used was baseline survey to find out gaps in existing knowledge, followed by development of draft materials, which were then pretested before final revision and printing.

\section{METHOD OF PAMPHLET DEVELOPMENT}

\section{(a) Baseline survey}

A survey was done to get an overview of the baseline knowledge of people on general issues relating to appropriate drug use. The members of the study team designed a questionnaire based on some priority issues related to basic do's and don'ts about medicine use by consumers. The questionnaire was pretested on a total of 25 respondents. Based on the results of the pretest, certain modifications were made in the questionnaire before using it for actual data collection.

The technique used for data collection was personal interview. The answers given by each respondent were recorded by the interviewer onto the questionnaire sheet.

The pretesting and the actual data collection were done by nine Proficiency Certificate Level Pharmacy (PCL Pharmacy) students of IOM. All of them were trained by the study team members about: details of approaching the respondents; explaining what was being done; the order and manner of asking questions; and the style of recording answers in the questionnaires. The data collection procedures were supervised and monitored by the study team members. 
The survey sample consisted of visitors of patients admitted to all the wards of TUTH. While in the ward, all adult visitors were approached for interview. Of a total of 765 persons approached, successful interviews were taken from 604; one hundred fifty one were unwilling to give interview and a further 10 were excluded from interview because they were found to have health background. On an average each interview lasted about 10 minutes. Pretesting was done on 3 and 4 August 1999 and the actual data were collected between 5 and 16 August 1999.

The findings of the baseline survey are given in Table 1. The Table also identifies issues and gaps in knowledge that formed the basis for further work on the project.

Table I: Level of awareness of respondents on basic do's and don'ts about medicines $(\mathbf{n}=604)$ 


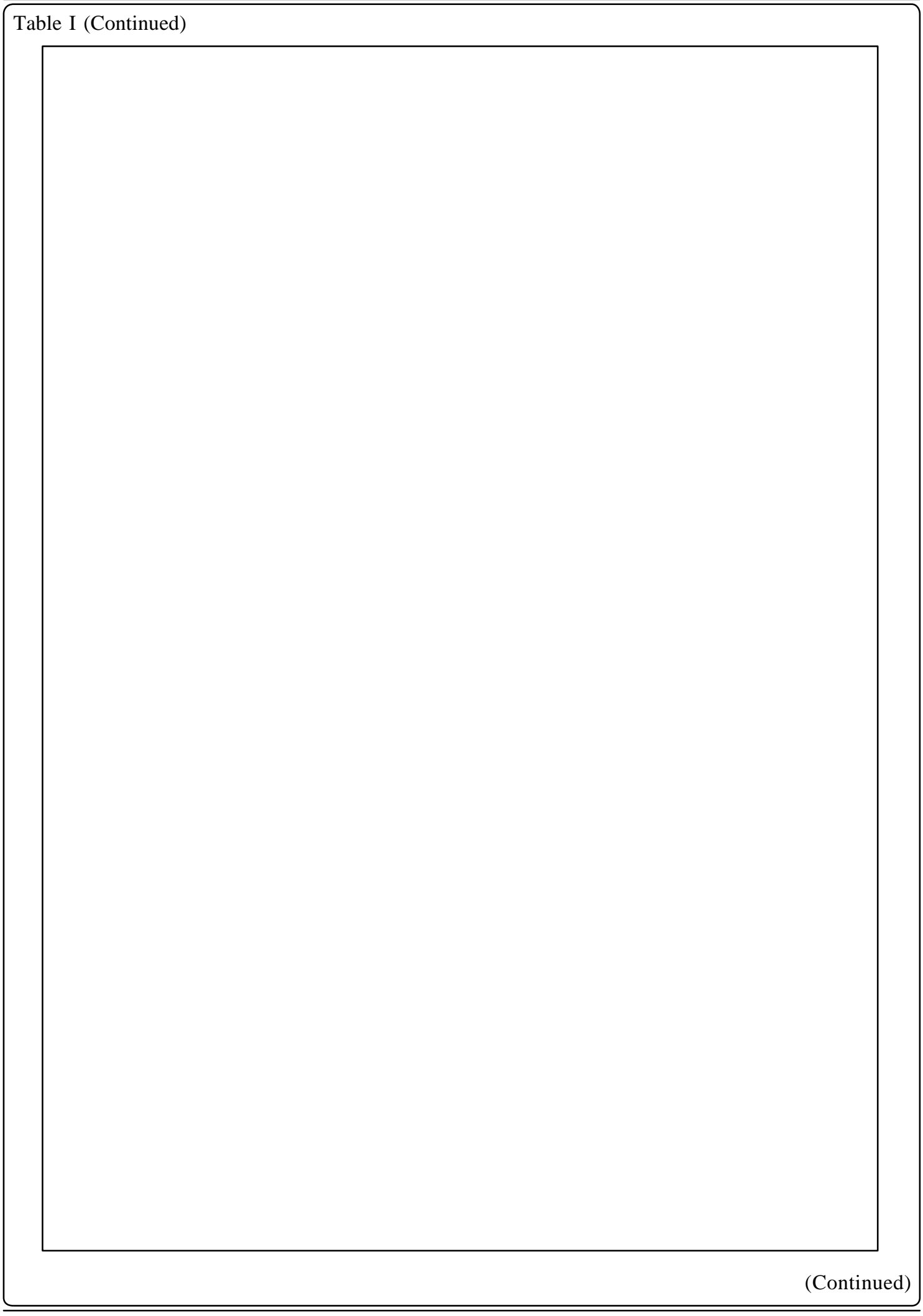

JNMA, October - December, 2002, 41 


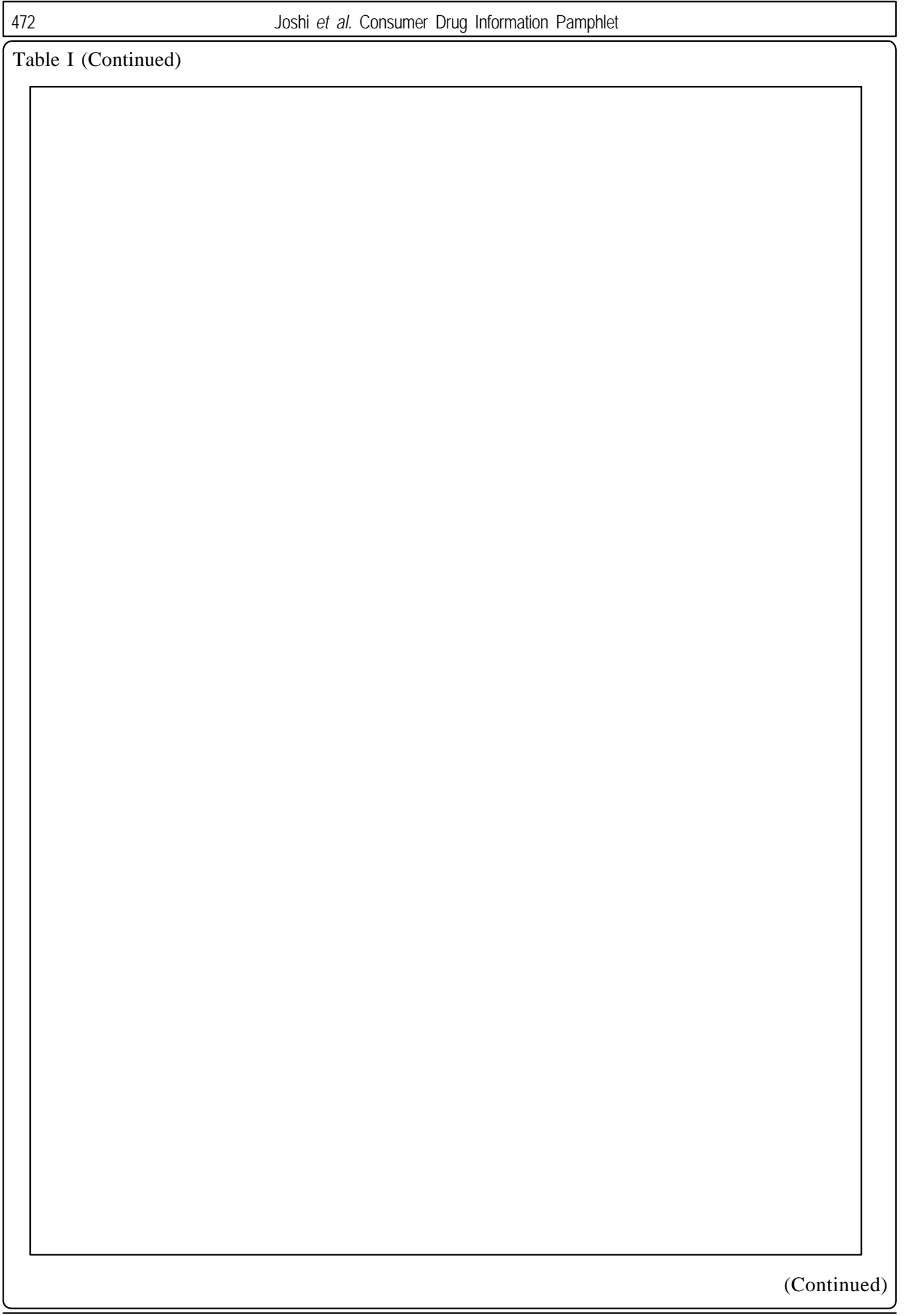

JNMA, October - December, 2002, 41 


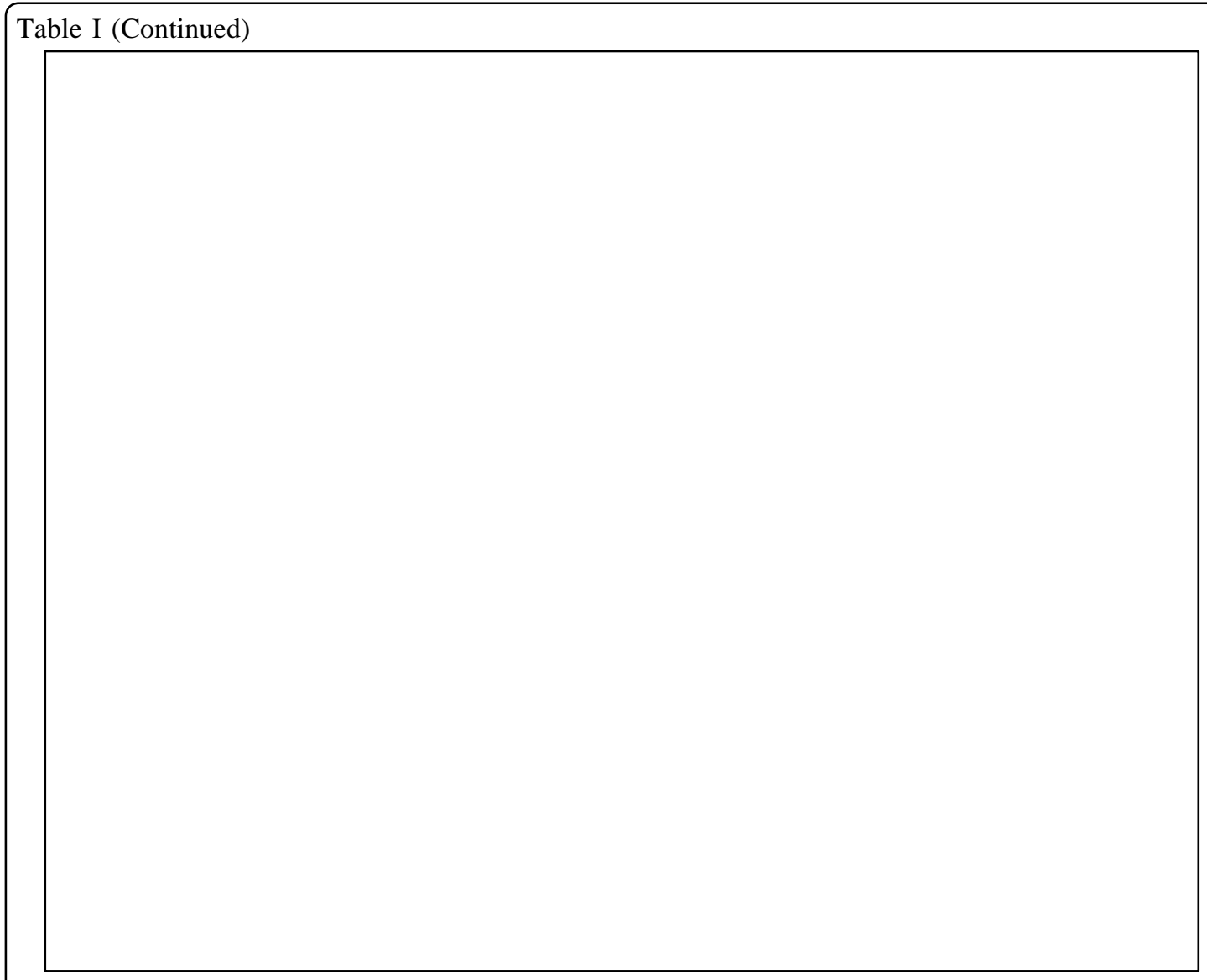

Note: The total number of responses for some of the questions adds up to more than 100\% because of multiple responses.

\section{(b) Pretesting of the draft pamphlet}

Based on the findings of the above baseline survey, a draft pamphlet emphasizing key messages was developed by the study team. The content of the draft pamphlet was designed to address the issues and areas about which the respondents were found to be least knowledgeable. The language used was Nepali. The information included in the draft was carefully prioritized because of the limitation of the available space, which consisted of two sides of A4 sheet. The study team decided to limit the space to two pages (front and back) of A4 sheet, mainly because of cost and also because of the thought that a lengthy print with a lot of crammed up information might be less likely to be read by the people. The team took help of a graphic designer cum illustrator for layout of and drawings for the draft pamphlet.

The draft pamphlet was pretested on visitors/ caregivers of patients admitted to all the wards of TUTH. This pretest was done from 24 to 29 August 1999. The process was supervised the team members. A total of 951 visitors were approached for interview. Out of these, successful interviews were taken from 614 visitors. Health workers $(n=12)$, illiterate visitors $(n=298)$, and those who were unwilling $(n=27)$ were excluded from the pretest. The method of pretest consisted of first giving the draft pamphlet to each respondent to read for about 10 minutes and then asking 
questions to each of them, mainly pertaining to presents the results of this pretest. It also indicates the clarity of the content, language and drawings the revisions made in the pamphlet based on the in the pamphlet. The interviewer recorded the suggestions received.

responses in the questionnaire sheet. Table 2

Table II: Pretest of the draft pamphlet on the visitors/caregivers $(n=614)$ of patients admitted to TUTH wards: the questions asked, responses given, and subsequent revisions made in the pamphlet.

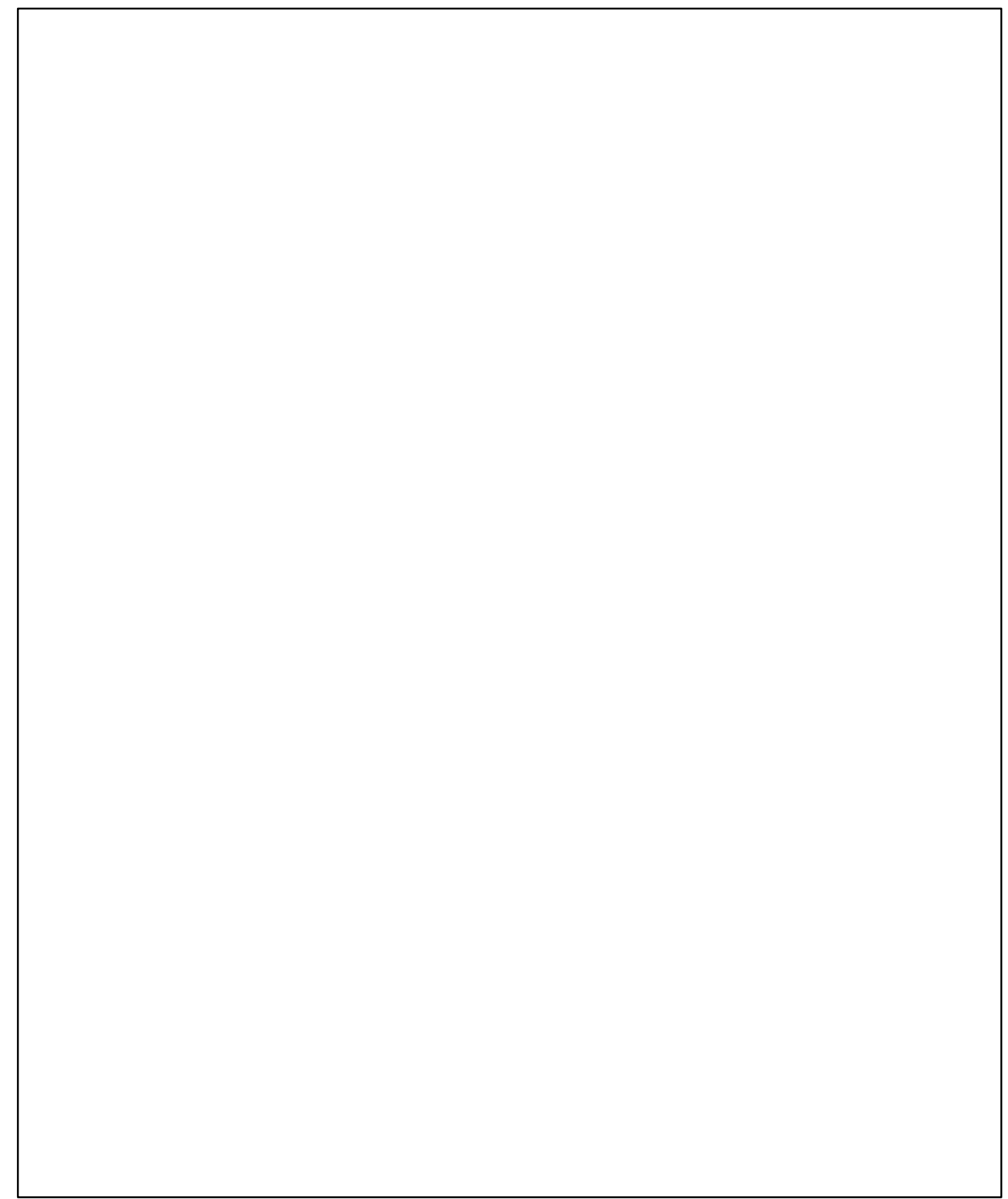

(Continued)

JNMA, October - December, 2002, 41 
Table II (Continued)

The draft pamphlet was also distributed to a total of 11 subject experts (pharmacists and prescribing doctors) for free comments. Additionally, the pamphlet was given to two Nepali language experts for comments on the language. The comments given by them are presented in Table 3 .

Table III: Pretesting on experts (pharmacists, medical doctors, and Nepali language experts) (n=13)

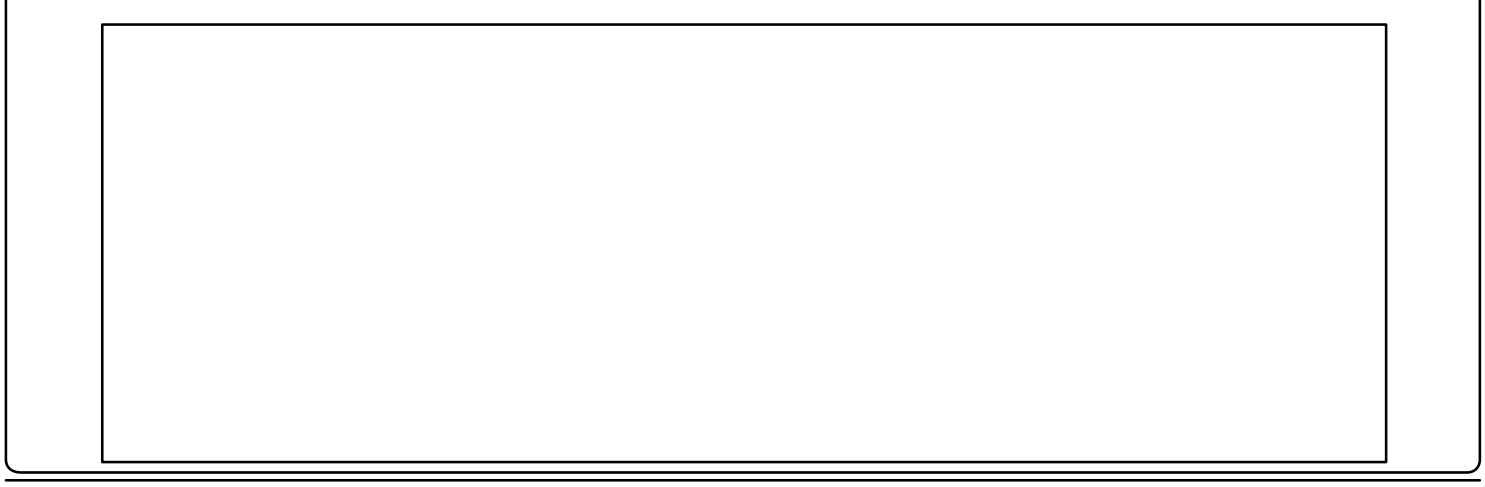

JNMA, October - December, 2002, 41 
(c) Revision and printing of the pamphlet

As is evident from Tables 2 and 3, several useful comments and suggestions were received during the pretest of the draft pamphlet. Most of them pertained to the drawings. Some were related to the content of the text. A few were related to the language and size of the letters. Most of these suggestions were incorporated while revising the pamphlet (Tables 2 and 3).

To save on cost, only one color was used for printing. The color of the background paper used was light yellow. The letters and drawings were printed in dark coffee color. The pamphlet was designed into a 3 -fold sheet with a view to making it convenient to carry in hand or pocket. The cost of printing was quite low. At delivery, 55 pamphlets cost just one US Dollar. A total of 27 thousand pamphlets were printed. The pamphlet is presented as Appendix 1.

\section{DISCUSSION}

Inappropriate drug use is a common problem all over the world. ${ }^{13-21}$ Factors that contribute to this problem include improper prescribing by health workers, unethical practices of manufacturers and traders, and weakness of drug regulatory authorities. In addition, ignorance of consumers contributes to this problem. Literature indicates that people have different misconceptions about drugs and misuse them. ${ }^{13}$

There is often inadequate communication, particularly in developing countries, between the public who consume medicines and those who prescribe, dispense, administer and regulate drugs. ${ }^{21-23}$ The situation is not different in Nepal.

Public education programs have so far received generally low priorities. Possible reasons include:
(1) belief that promotional information given by drug manufacturers is enough to meet consumer needs, (2) health professionals' paternalistic attitude towards patients and the public, (3) feeling that public education may not be valuable, (4) lack of confidence and/or knowledge on the part of health care professionals as to their ability to provide such education, and (5) opposition by vested interests which may make it difficult to gain support for such activities. Lack of availability of qualified personnel in the field of public education, particularly in developing countries, is another constraining factor. ${ }^{13}$ These different reasons may negatively affect the planning of activities as well as their implementation and evaluation. The resultant weaknesses in outcome may in turn lead to further difficulties in obtaining support and funding for future activities. A lot of advocacy at national, regional and international level is thus needed to increase the level of support for such activities. Apart from advocacy, other important requirements include operations research, development of effective training documents/tools, technical assistance, and financial support. ${ }^{24}$

Just as in many other developing countries, very little had been done in Nepal until the recent past regarding public education on proper drug use. However, there is now a growing realization of the value of such work and the present work represents an effort in this area.

The ultimate aim of education is to create positive behavior change in the public. But this does not happen quickly. It is usually a long-term process and often requires continued commitment. Behavior change occurs along a long continuum, the beginning of which is the creation of awareness. ${ }^{13}$ The present work of DIU is an attempt towards development of material that assists in the creation of such awareness. 
Production of suitable and effective print material requires attention to a lot of details. The material needs to be developed in the local context. It should be simple, believable and personally relevant. The write-up should be in the local language that includes terms and styles used by the majority of target audience. As far as possible the messages should be action-orientated, with focus on what to do, rather than what not to do. The illustrations should be culturally specific and well-drawn. What is intended to communicate through the drawings should be clearly recognizable. The drawings should reinforce the corresponding message in the text. There should be a good match between the text and the graphics. Importantly, cramming up of too many messages should be avoided. Gender bias should be avoided. ${ }^{25,26}$ Careful attention was paid to these details while developing the present material by DIU. Feedback from subject experts, language experts, graphic designer, and members of the target audience in the real world setting greatly helped to refine and improve the pamphlet before final printing.

IOM students studying PCL Course in Pharmacy were involved in data collection. Therefore, in addition to achieving the primary goal of producing the pamphlet, the present work could also provide some practical exposure to pharmacy students on drug education related research and communication with the public.

Distribution of a material is as important as its development. The pamphlets developed by DIU were distributed free of charge to patients, caregivers and visitors attending the TUTH. Distribution was done mainly from the TUTH Dispensary when people came there to buy medicines. Limited copies of the pamphlet were also sent to government health institutions, nongovernment organizations, and other health-related organizations in Nepal.

\section{ACKNOWLEDGMENTS}

We gratefully acknowledge the financial support provided by U.S. Agency for International Development (USAID) and U.S. Pharmacopeia (USP) for doing this work.

We are grateful to the following students of PCL course in Pharmacy for their help in data collection: Pushpa Rana Chhetri, Rakesh Karn, Nayana Shrestha, Kiran Sundar Bajracharya, Rudip Piya, Sachita Joshi, Shirish Aryal, Sharmila Shrestha and Nirajan Bhushal.

We record our gratefulness to Mr Uttam Kharel, who made all the illustrations for the pamphlet. We also record our gratefulness to all the experts who provided comments and suggestions on the draft pamphlet.

\section{REFERENCES}

1. P rofile of the $I$ nstitute of $M$ edicine, $K$ athmandu: I nstitute of M edicine, $T$ ribhuvan $U$ niversity, 2001.

2. J oshi MP. U niversity hospital-based drug information service in a devel oping country. $E$ ur J C lin P harmacol 1997; 53: 89-94.

3. J oshi M P. D rug information service at teaching hospitals in developing countries. I ndian J ournal of $\mathrm{P}$ harmacology 1998; 30: 1-5.

4. T U T eaching $H$ ospital Formulary. J ournal of the I nstitute of M edicine 1997; 19 (supplement): 1- 29 .

5. J oshi $M P$, ed. $P$ roblem-orientated training on rational therapeutics. $K$ athmandu: $M$ edical $E$ ducation $D$ epartment, I nstitute of $M$ edicine, T ribhuvan U niversity, 1999.

6. J oshi M $P, K$ hakurel $B K, R$ aut $K B$, eds. $P$ roblembased training on rational antimicrobial therapy, $K$ athmandu: I nstitute of $M$ edicine, $T$ ribhuvan U niversity, 2001. 
7. J oshi M P, O nta S, K hakurel B K, B hattarai K. $R$ ational drug use workshops in $N$ epal for consumers. J ournal of the I nstitute of $M$ edicine 1999; 21: 62-81.

8. J oshi M P, K hakurel B K, U preti R P.U pabhoktale aushadhi bare jannaiparne tathyaharu (F acts about medicines that consumers must know), $\mathrm{K}$ athmandu: $\mathrm{N}$ epal $\mathrm{H}$ ealth $\mathrm{R}$ esearch C ouncil, 1997 (in N epali language).

9. J oshi M P, S hrestha B M, S hrestha P K, S hrestha $C K, H$ ousley $D, J$ ohnson $K$. D rug I nformation $\mathrm{N}$ etwork of $\mathrm{N}$ epal: an innovative approach to the provision of information. I N R U D N ews 1996; 6 (2): $16-17$.

10. D rug information in $N$ epal: bringing professionals together. E ssential D rugs M onitor, 1996, I ssue $\mathrm{N} 0.22$, page 15 .

11. $Q$ uickJ $D, R$ ankin $R, L$ aing $R, 0$ 'C onnor $R W$, $H$ ogerzeil $H V, D$ ukes $M N G, G$ arnett $A$. M anaging drug supply: the selection, procurement, distribution and use of pharmaceuticals, second edition. $M$ anagement $S$ ciences for $H$ ealth and $\mathrm{W}$ orld $\mathrm{H}$ eal th $\mathrm{O}$ rganization, $\mathrm{C}$ onnecticut: $\mathrm{K}$ umarian P ress, 1997.

12. P ublic education in drug use: a growing need. E ssential D rugs M onitor, I ssue N 0.18, 1994, pages $14-16$.

13. F resle $D A, W$ ol fheim $C, P$ ublic education in rational drug use: a global survey. $G$ eneva: A ction $P$ rogramme on $E$ ssential $D$ rugs, $W$ orld $H$ ealth 0 rganization, 1997 (W H O /D A P /97.5). [Q uoted with written permission from $W \mathrm{H} \mathrm{O}, \mathrm{G}$ eneva.]

14. L aing $R \quad 0, R$ ational drug use: an unsolved problem. T ropical D octor 1990; 20: 101-103.

15. H ogerzeil $H V$ V.P romoting rational prescribing: an international perspective. B $\mathrm{r}$ J C Iin P harmac 1995; 39: $1-6$.

16. $H$ ardon $A, G$ eest $S$ van der, eds. $T$ he provision and use of drugs in developing countries: a review of studies and annotated bibliography. A msterdam: $\mathrm{H}$ et $\mathrm{S}$ pinhuis and H A I - E urope, 1991.
17. J oshi M P.R ational prescribing. I $\mathrm{n}$ : J oshi $M P$, A dhikari $R K$, eds. $M$ anual of drugs and therapeuties. $K$ athmandu: $H$ ealth $L$ earning $M$ aterials $C$ entre, I nstitute of $M$ edicine, $T$ ribhuvan U niversity, 1996: 1-10.

18. W H O P olicy P erspectives on M edicines $P$ romoting rational use of medicines: core components. $G$ eneva: $W$ orld $H$ eal th 0 rganization, 2002 (W H O/E D M /2002.3)

19. H asnain M. U nderstanding rational therapeutics: therapeutics is something more than prescribing drugs. I slamabad, P akistan: I slamabad M edical P ublications, 1997.

20. B ush $\mathrm{PJ}, \mathrm{H}$ ardon $\mathrm{A} P$. T owards rational medicine use: is there a role for children? Soc S ci M ed 1990; 31(9): 1043-1050.

21. P ublic education in rational drug use: report of an informal consultation, $G$ eneva, 23-26 N ovember 1993. G eneva: A ction P rogramme on $E$ ssential $D$ rugs, $W$ orld $\mathrm{H}$ ealth 0 rganization, 1994 (W H O / D A P /94.1) [Q uoted with written permission from W H $0, G$ eneva.]

22. M edawar C.D rug and world $\mathrm{H}$ eal th. $\mathrm{H}$ olland: $\mathrm{S}$ ocial A udit,I O C U, 1984.

23. J oshi $M P, W$ achter $D A$,J ohnson $K W, R$ egmi $B M$, T amrakar $R K, R$ anjitkar $S$ et al. $P$ hysician-patient communication regarding prescribed medication in an ambulatory care setting in $K$ athmandu, $\mathrm{N}$ epal. J ournal of $\mathrm{N}$ epal $\mathrm{M}$ edical A ssociation 2001; 40: 1-5.

24. R ational drug use: consumer education and information. A ction $P$ rogramme on $E$ ssential $D$ rugs, $W$ orld $H$ ealth 0 rganization, 1996 (D A P / M A C (8)/96.6). [Q uoted with written permission from W H $0, G$ eneva.]

25. D raft guide to evaluating medicine education programs and materials for consumers. $R$ ockville, M D : U nited S tates P harmacopeia, 1998.

26. S oumerai S. D eveloping and evaluating printed educational and training materials. I N R U D N ews 1992; 3(1): 13-14. 


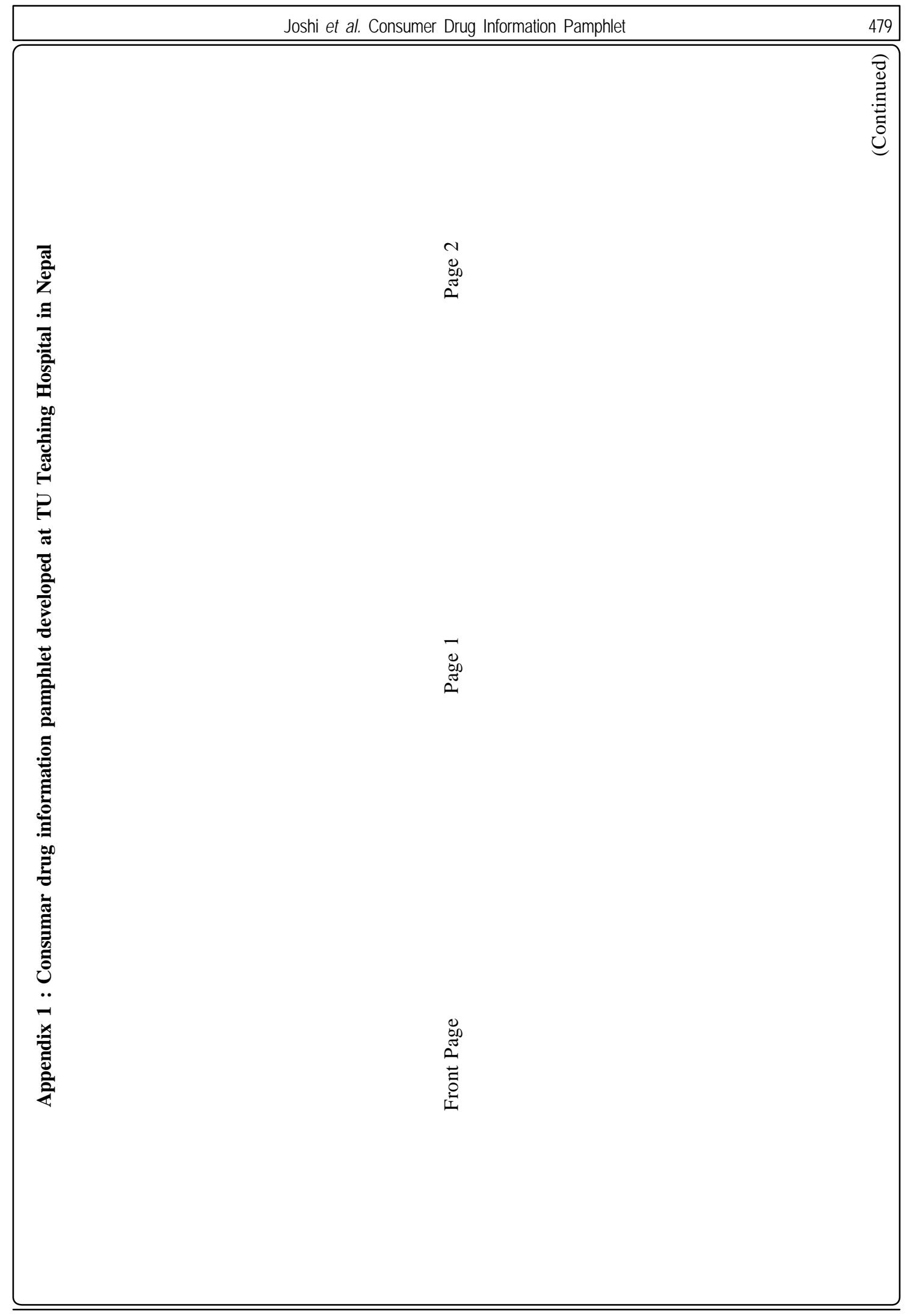

JNMA, October - December, 2002, 41 
480 Joshi et al. Consumer Drug Information Pamphlet

$n$
0
on
$\pi$

$\underset{0}{+}$

氕

$n$
0
0
0
0

JNMA, October - December, 2002, 41 